Advertising and price effectiveness over the business cycle

M.J. Gijsenberg, H.J. van Heerde, M.G. Dekimpe and J.-B.E.M. Steenkamp

DEPARTMENT OF MARKETING AND ORGANISATION STUDIES (MO) 


\title{
ADVERTISING AND PRICE EFFECTIVENESS OVER THE BUSINESS CYCLE
}

\author{
Maarten J. Gijsenberg \\ Harald J. van Heerde \\ Marnik G. Dekimpe \\ Jan-Benedict E.M. Steenkamp
}

June 11, 2009

Maarten J. Gijsenberg is a Doctoral Candidate at the Catholic University of Leuven and Researcher in Marketing at the Louvain School of Management \& FUCaM (e-mail: maarten.gijsenberg@fucam.ac.be). Harald J. van Heerde is Professor of Marketing at the Waikato Management School, University of Waikato (e-mail: heerde@mngt.waikato.ac.nz). Marnik G. Dekimpe is Research Professor of Marketing \& CentER Fellow at Tilburg University, and Professor of Marketing at the Catholic University of Leuven (e-mail: m.g.dekimpe@uvt.nl). JanBenedict E.M. Steenkamp is C. Knox Massey Distinguished Professor of Marketing and Marketing Area Chair, Kenan-Flager Business School, University of North Carolina at Chapel Hill (e-mail: jbs@unc.edu). 


\title{
ADVERTISING AND PRICING EFFECTIVENESS \\ OVER THE BUSINESS CYCLE
}

\begin{abstract}
In this study, the authors conduct a systematic investigation on the evolution in the effectiveness of two important marketing mix instruments, advertising and price, over the business cycle. Analyses are based on 163 branded products in 37 mature CPG categories in the UK, and this for a period of 15 years. The data are a combination of (i) monthly national sales data, (ii) monthly advertising data, (iii) data on the general economic conditions, and (iv) consumer survey data. Consumers are shown to be more price sensitive during contractions. In addition, spending patterns will be less consistent, implying smaller brand loyalty. Advertising elasticities, however, do not seem to be affected by economic downturns. Product involvement was shown to be an influential moderator of the final effect of advertising, price and carry-over effects on sales. Finally, although short run effectiveness of price differs between expansions and contractions, the long run effectiveness of both advertising and price is not altered by differences in the general economic conditions.
\end{abstract}

Key words: Advertising, Price, Effectiveness, Business Cycle, time-series econometrics, Bayesian inference 


\section{Introduction}

Firms are under ever increasing pressure to justify their marketing expenditures. Once considered mere costs, these expenditures are more and more treated as investments that should deliver shareholder value (e.g. Srivastava et al., 1999). Improvement of the performance and accountability of their organizations are consequently top concerns for senior marketing managers (CMO Council, 2009) since “...companies are more interested than ever in understanding and measuring the returns being obtained from marketing investments..." (Marketing Science Institute, 2008).

This evolution towards greater accountability is reinforced in times of economic contractions, as every dollar starts to matter more. Firms facing difficult times tighten their belts, and marketing budgets are among the first to be reconsidered (McKinsey Global Survey, 2009). The recent economic downturn is no exception to this (The Financial Times, 2008). Late 2008, Toyota Motor USA, for example, announced a cut of $10 \%$ across all marketing budgets, while GM announced economizing up to $\$ 600$ million on its advertising and promotion budget up to 2012. By January 2009, 71\% of all marketing managers had reduced their advertising budgets, while $77 \%$ was planning to cut their media expenditures (AdAge, 2009). These examples illustrate that as the economy cools down, managers feel even more strongly the need to reconsider their marketing investments.

While there exists a considerable body of literature on marketing-mix effectiveness and elasticities in general (see e.g. Bijmolt et al., 2005; Hanssens, 2009 for recent overviews), previous research has not linked this to the business cycle. Does the effectiveness of marketing mix instruments vary across the business cycle, and if so, in what direction? What is the magnitude of the variation? Are there differences across marketing mix instruments, across brands and/or across categories? Although the subject of an intense debate, no systematic effort has been undertaken to provide answers to these questions. From a managerial point of view, insight into these questions helps companies in formulating their response to economic downturns. It provides them with a better understanding of the effectiveness of their investments. This enables them to better spread tighter budgets over the different marketing mix instruments, thereby answering the call for improved performance and accountability of the marketing 
organization. From an academic point of view, it is important to understand how the effectiveness of marketing mix instruments varies systematically over the business cycle. A good understanding of this evolution, is likely to add to our understanding of other observed phenomena as well. Private label success, for instance, has been shown to exhibit cyclical patterns, with systematic market share gains during downturns (Lamey et al, 2007). The purpose of the current study is to provide insights in these issues for two important marketing mix instruments, viz. Advertising and Price.

The remainder of this paper is structured as follows. We first review the previous literature (Section 2), and describe how and why marketing effectiveness may vary across the business cycle (Section 3). We subsequently explain the extraction of the business cycle components and the applied methodology in assessing the impact of the business cycle on advertising effectiveness (Section 4). Next, we describe our data (Section 5), and present our empirical findings (Section 6) and managerial implications (Section 7).

\section{Relevant literature}

The present study integrates three lines of research. Since the early days of marketing research, advertising and pricing effectiveness have been the subject of numerous studies, making them among the best covered issues in marketing science. More recently, a body of research focusing on marketing decisions over the business cycle has emerged.

\section{Advertising effectiveness}

Advertising effectiveness has been the focus of an impressive body of research (e.g. Lambin et al., 1975; Vakratsas and Ambler, 1999; for recent overviews, see Tellis and Ambler, 2007 or Hanssens, 2009). One of the first empirical generalizations in the domain was derived by Clarke (1976), who showed that $90 \%$ of the cumulative impact of advertising on sales occurred within months (and not years) of the advertisement. The advertising carry-over parameter $\lambda$ of the Koyck model, which was driving this result, was reported to have a grand mean of 0.76 (Clarke, 1976). Assmuss et al. (1984) analyzed 128 studies assessing the impact of advertising on 
sales. They found the short-run advertising elasticity to have a grand mean of 0.221 . In addition, they showed that not accounting for carry-over effects of advertising lead to considerable biases in the estimated short run effectiveness. A meta-analysis by Sethuraman and Tellis (1991) found the average short-run advertising elasticity to be only half of the previously mentioned value (0.109), according to the authors a possible consequence of people becoming more used to advertising.

Advertising has been shown to be relatively less effective for mature versus new products (Lodish et al., 1995). The authors also pointed out that spending more may not result in increased sales for well established and frequently advertising brands, indicating that they may already be advertising at saturation levels. Other studies showed advertising effectiveness to vary systematically with the level of involvement with the product (Krugman, 1965) and the perceived risk associated with buying the product (Sheth and Venkatesan, 1968).

Based on these insights, we will control for product class and involvement when assessing the impact of economic fluctuations on advertising effectiveness. In addition, we will explicitly allow for carry-over effects.

\section{Price effectiveness}

Not surprisingly, also the quantification of the price effectiveness has received considerable research attention. In a first large-scale meta-analysis, Tellis (1988) covered over 367 elasticities related to 220 different brands or markets. The reported mean of -1.76 was considerably larger than the average advertising elasticity. A new meta-analysis by Bijmolt et al. (2004), based on 1851 elasticities, found the average price elasticity to be considerably higher than the one reported by Tellis (1988), i.e. -2.62. Higher inflation levels, in addition, were found to increase the price sensitivity, especially in the short run.

Similar to advertising elasticities, variation of price elasticities across brands and categories has been documented. Simon (1979) found a U-shaped relationship between the magnitude of price elasticities and the product life cycle, while Tellis (1988) reported stronger price sensitivities in the later stages of the product life cycle. Bijmolt et al. (2004), in turn, reported declining elasticies over the PLC. Finally, Sethuraman and Tellis (1991) examined the price/advertising elasticity ratio. They reported higher ratios for more mature products, which 
implies that lowering prices may be more profitable than increasing advertising for such categories.

\section{Marketing decision making over the business cycle}

Clearly, both marketing instruments have been studied extensively in prior research. However, we are not aware of any studies that have systematically linked these instruments' effectiveness to the state of the economy, and its evolution through subsequent expansions and contractions. Though the linkage between such macro-economic fluctuations and marketing decision making, in contrast, has received increasing attention over the last few years, as reviewed in Table 1.

A recurring finding in these studies is the fact that counter-cyclical advertising actions during economic downturns can create value for the company (Frankenberger \& Graham, 2003; Srinivasan et al., 2005; Deleersnyder et al., 2009; Srinivasan and Lilien, 2009), which has been attributed indirectly to a presumed higher effectiveness during those periods. Other studies have focused on the level of marketing spending during contractions and expansions. Deleersnyder et al. (2009) showed that advertising expenditures are particularly sensitive to business cycle fluctuations, with strong increases during expansions and decreases during contractions. Such pro-cyclical advertising behavior, in combination with an increased price awareness during less favorable economic conditions (Estelami et al., 2001), has been linked with higher private label growth (Lamey et al., 2007; Deleersnyder et al., 2009). Private label share not only follows a counter-cyclical pattern, but also shows deepness and steepness asymmetries, with higher and faster growth during contractions and smaller and slower decline during expansions (Lamey et al., 2007). Pro-cyclical behavior, in turn, has also been observed in the context of new-productintroductions, where fewer new products tend to be be introduced during economic downturns (e.g. Devinney, 1991; Axarloglou, 2003).

Moreover, pro-cyclical sales tendencies, whether or not due to pro-cyclical marketing expenditures, moreover, are a widespread phenomenon for branded products. They do not only exist in CPG markets, but are also reported in durables markets, which also tend to exhibit a faster decline than recovery (Deleersnyder et al., 2004). 
Table 1. Previous studies on marketing decisions over the business cycle

\begin{tabular}{|c|c|c|}
\hline Study & Key Metric & Main Findings \\
\hline Devinney (1991) & New Product Introductions & $\begin{array}{l}\text { Fewer new products are launched during } \\
\text { economic downturns }\end{array}$ \\
\hline Estelami et al. (2001) & Consumer Price Knowledge & $\begin{array}{l}\text { Consumers are less price aware in economic } \\
\text { upbeat times }\end{array}$ \\
\hline Axarloglou (2003) & New Product Introductions & $\begin{array}{l}\text { Fewer new products are launched during } \\
\text { economic downturns }\end{array}$ \\
\hline Frankenberger \& Graham (2003) & Financial Performance & $\begin{array}{l}\text { Increases in advertising expenditures (especially } \\
\text { in combination with the introduction of new } \\
\text { products) during crises create added value }\end{array}$ \\
\hline Deleersnyder et al. (2004) & Durables' Sales & $\begin{array}{l}\text { Durables show a pro-cyclical sales pattern } \\
\text { Steepness asymmetry: decline is faster than } \\
\text { recovery }\end{array}$ \\
\hline Srinivasan et al. (2005) & Firm Performance & $\begin{array}{l}\text { Pro-active marketing during contractions can be } \\
\text { beneficial for brands with a strategic emphasis } \\
\text { on marketing }\end{array}$ \\
\hline Lamey et al. (2007) & Private Label Sales & $\begin{array}{l}\text { Private label sales are higher during contractions } \\
\text { Deepness and steepness asymmetries: decline is } \\
\text { stronger and faster than recovery. Part of the } \\
\text { private-label gain during contractions }\end{array}$ \\
\hline \multirow[t]{3}{*}{ Deleersnyder et al. (2009) } & Advertising Spending & $\begin{array}{l}\text { Advertising spending shows a pro-cyclical } \\
\text { pattern }\end{array}$ \\
\hline & Private Label Sales & $\begin{array}{l}\text { More pro-cyclical advertising spending is } \\
\text { associated with higher private label growth }\end{array}$ \\
\hline & Firm Performance & $\begin{array}{l}\text { Lower stock price performance for companies } \\
\text { with pro-cyclical advertising patterns }\end{array}$ \\
\hline Srinivasan and Lilien (2009) & Financial Performance & $\begin{array}{l}\text { Increased R\&D spending during contractions } \\
\text { lower profits in B2B and B2C } \\
\text { Increased advertising spending during } \\
\text { contractions increase profits in B2B and B2C } \\
\text { Effects last the year after the contractions }\end{array}$ \\
\hline
\end{tabular}

This overview shows the increasing attention for the linkage between marketing decision making and the state of the economy. These studies, however, provide little to no evidence on the effectiveness of these decisions under different (expansion versus contraction) conditions. To address this issue, we derive the advertising and price elasticity of over 160 branded products in close to $40 \mathrm{CPG}$ categories. This will allow us to not only derive empirical generalizations, but also to determine whether all brands/categories are equally affected by changing economic conditions.

The data span over 15 years of monthly data. The length of the time series allows us to cover multiple business cycles. As a result, inferences will not be driven by the idiosyncrasies of one specific expansion or contraction period (for a similar reasoning, see Deleersnyder et al., 
2009, who also cover multiple business cycles). The disaggregate nature of the series, with their monthly observations, helps us to resolve two important issues. First, the periodicity of business cycles is 1.5 to 8 years (e.g. Burns and Mitchell, 1946; Christiano and Fitzgerald, 1998). When using annual data, the Nyquist frequency, i.e. the highest frequency about which direct information is available, corresponds to a component of 2 years (Granger and Hatanaka, 1964; Vilasuso, 1997). Higher frequency phenomena, i.e. short run fluctuations with a duration of less than 2 years, would hence not be removed from the data series. More disaggregated data, on the contrary, enable us to eliminate those higher frequencies as well. Second, from a market response perspective, annual data would introduce an aggregation bias in our analyses and inferences (see e.g. Hanssens et al., 2001). The usage of monthly data will mitigate this problem.

\section{Framework and Hypotheses}

The conceptual framework guiding our work is depicted in figure 1. We argue sales to depend on two main types of factors: marketing-mix related factors, and macro-economic related factors. The final effects of these factors on sales are affected by the level of product-involvement the consumers show in the product category.

\subsection{Cyclical sensitivity of sales}

Economic downturns have a direct impact on both the ability and the willingness of consumers to spend their financial means. During economic sour times, consumers have fewer means at their disposal. In addition, consumers easily loose trust during contractions. As trust is a key factor in consumers' willingness to buy (e.g. Katona, 1975; Kamakura and Gessner, 1986; Allenby et al, 1996), they become hesitant to spend their money. Consumers have also been shown to easily switch to private-label offerings during economic downturns (Lamey et al, 2007), which further reduces the sales of branded products. As such, we expect a negative main effect of an economic contraction on brand sales. 


\subsection{Cyclical sensitivity of marketing effectiveness}

Advertising. Although the overall elasticities have been found to be rather small (Asmuss et al., 1984; Sethuraman and Tellis, 1991), advertising still has a positive effect on sales. During economic downturns, this elasticity may increase. Overall reductions in advertising budgets (e.g. Deleersnyder et al, 2009) will give firms better chances in reaching the customer, as the firms face less competitive clutter (Danaher et al., 2008). At the same time, media rates are lower during contractions (e.g. AdAge, 2009). Further, increased advertising spending during economic tight times has been shown to positively influence firm profits (Srinivasan and Lilien, 2009), implying possibly higher advertising effectiveness. These profits, on the other hand, may also be higher as a consequence of price increases during downturns (e.g. Backus and Kehoe, 1992; Rotemberg and Saloner, 1986; Rotemberg and Woodford, 1999; Deleersnyder et al., 2004), without advertising becoming more effective. By means of such price increases, firms try to make up for reduced sales quantities, thus preserving overall profits. In addition, during contractions, consumers focus more on the functional aspects of products instead of hedonic aspects as e.g. brand image, built by advertising (e.g. Ang et al., 2000). As a consequence, they may show lower reactivity to advertising, thus lowering the effectiveness of the advertising investments. The net effect of these processes on advertising elasticity is not clear a priori.

Figure 1. Conceptual framework.

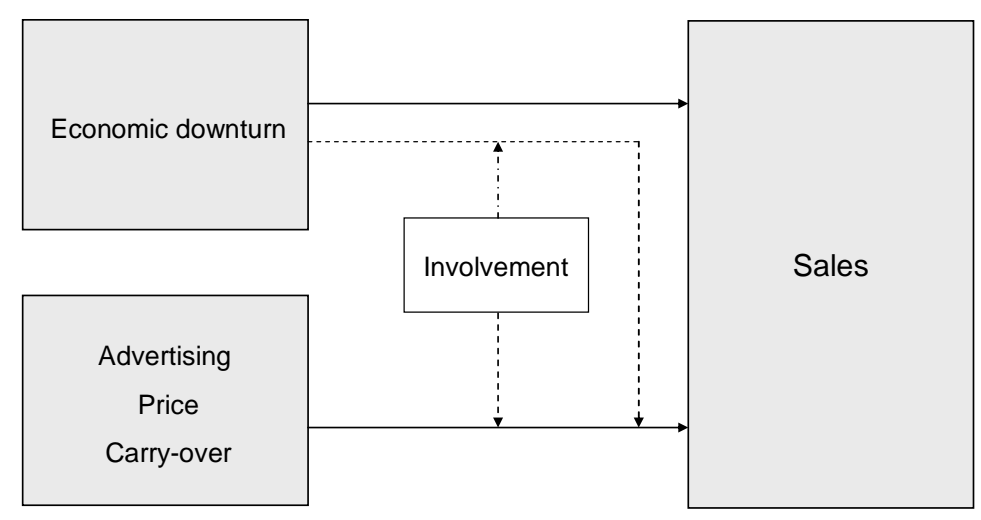

Pricing. In their 2005 meta-analysis, Bijmolt et al show that the average price-elasticity equals -2.62 . Common sense tells that during economic downturns, this elasticity will become even more negative (e.g. Block, 1979). Consumers' disposable income is usually lower in such 
periods, creating a higher level of price awareness and fostering a search for lower prices (Wakefield and Inman, 1993; Estelami et al, 2001). They express stronger appreciation for price cuts (Quelch, 2008), and are shown to switch to lower priced private label offerings (e.g. Quelch and Harding, 1996; Ang et al, 2000; Lamey et al, 2007). We therefore expect an increase in the magnitude of price elasticities during economic downturns

Carry-over. Besides the short run effectiveness of advertising and pricing, as captured by the previous variables, we are also interested in their long-run performance. The long run performance may not only change as a consequence of changing short-run elasticities, but also because of different carry-over effects across the business cycle, as brand loyalty is likely to be lower during contractions. First, when the economy turns sour, consumers experience a larger pressure on their disposable income. As a consequence, they show stronger switching behavior, and less brand loyalty (Chance and French, 1972). At each decision, consumers will engage in increased information gathering, thereby evaluating several alternative options to get the maximum out of their smaller budgets, (e.g. Block, 1979; Wakefield and Inman, 1993). Second, lower brand loyalty will translate into lower carry-over effects as brand loyalty implies a consistent purchase of the brand over time (Keller, 1993; Assael, 1998). Stronger switching behavior implies less consistent purchase patterns, and hence reduced carry-over. We consequently expect carry-over effects to be smaller during economic sour times.

\subsection{The moderating role of involvement}

Involvement is typically defined as the subjective perception of the personal relevance of an object, activity or situation (Van Trijp et al, 1996). Involvement will be higher with products that show considerable performance risk and symbolic value (Laurent and Kapferer, 1985). In high involvement product categories consumers engage in more profound information gathering and decision making processes (Bloch et al., 1986; Assael, 1998). Advertising messages, for example, will be more actively processed (e.g. Petty et al., 1983). At the same time, decisions will not be based on just one or two factors, but will be multi-dimensional, with consumers evaluating a larger set of criteria (Park and Mittal, 1985). As a consequence, the relative weight of each criterion will be smaller, and effects on the final sales decision will be smoothed by effects of other factors. Lower involvement categories, on the other hand, do not require such in- 
depth processes as e.g. the associated risk will be lower (Hoyer, 1984; Hawkins and Hoch, 1992). In such categories, people will rely more on heuristics in order to reduce their cognitive effort (Tversky and Kahneman, 1974), thereby basing their decisions on very little information. Among the most used heuristics are e.g price, brand awareness, advertising and previous purchases (Desphandé, 1982; Hoyer, 1984; Warrington and Shim, 2000). These heuristics tend to retain a dominant effect, even after multiple sampling opportunities of other brands (e.g. Hoyer and Brown, 1990). Given the smoothing effect in the more elaborate higher involvement product decisions relative to the amplification effect of the use of simple heuristics in lower involvement product decisions, we expect the effect of external cues like marketing mix instruments and macro-economic evolutions to be mitigated by the level of product involvement. This, in turn, results in lower advertising and price elasticities for higher involvement products. This effect will be reinforced during contractions, with the impact of contractions on the advertising and price elasticities being smaller for higher involvement products.

Brand loyalty, the consistent purchase of the same brand over time (Keller, 1993; Assael, 1998), however, can result from two clearly distinct processes. Brand loyalty has been argued to be one of the choice heuristics which are used to reduce cognitive effort and simplify decisions making for low involvement products (e.g. Warrington and Shim, 2000). In such cases, brand loyalty is nothing more than habitual buying behavior (e.g. Jeuland, 1979). Loyalty, on the other hand, can also be the outcome of in-depth information gathering processes in high involvement categories. Consumers have evaluated several different options in an elaborate process, and have concluded a certain brand to fit their requirements best (e.g. Newman and Staelin, 1972). Learning effects subsequently will play an important role in subsequent decisions (Newman and Staelin, 1972; Punj and Staelin, 1983). Hence, if higher involvement increases loyalty, carry-over is expected to be higher for higher involvement categories. Conversely, if higher involvement attenuates consumer inertia, carry-over will be lower for higher involvement categories. The final effect is not clear a priori.

\section{Methodology}

In order to provide an answer to the issues raised in previous sections, we propose a methodology which consists of three steps. First, we extract the cyclical component in the macro- 
economic indicator series using a business cycle filter, and determine contraction and expansion periods. Next, we formulate a model which quantifies the advertising and pricing elasticities both during contractions and expansions. Finally, we explain cross-category variation in the cyclical sensitivity of these elasticities.

\section{Extracting the cyclical component}

To assess the impact of business cycles on marketing mix effectiveness, we first have to extract the cyclical component from the GDP series, as the latter is a result of slowly evolving secular trends, a cyclical component and rapidly varying seasonal and irregular components (Baxter and King, 1999). In order to do so, we adopt the widely used $\underline{B} a x t e r-\underline{K}$ ing (1999) bandpass filter (e.g. Stock and Watson, 1999; Deleersnyder et al, 2004). This filter decomposes the GDP series in a gradually evolving long run trend component and cyclical fluctuations around it, the focus of our interest. The BK bandpass filter tries to isolate cycles with period lengths between 6 and 32 quarters, which corresponds to the typical length of business cycles (e.g. Burns and Mitchell, 1946; Christiano and Fitzgerald, 1998). The filter itself is a symmetric moving average filter:

$$
G D P_{t}^{C}=\sum_{j=-K}^{K} a_{j} L^{j} G D P_{t}
$$

where $G D P_{t}^{C}$ is the filtered series from the original time series $G D P_{t}$, with $a_{j}$ the weights corresponding to the different leads and lags. These weights are given in appendix A. K, the number of included leads and lags, is to be set equal to 12 for quarterly data (Baxter and King, 1999). The resulting filtered series, is the business cycle component series we are interested in. Although our study is based on monthly data, the least aggregated GDP series available, is on a quarterly level. We therefore analyze the GDP series at the quarterly level, and subsequently translate our findings to the monthly level.

In the marketing literature on turbulent times, several studies (e.g. Lamey et al, 2007; Deleersnyder et al, 2009) adopted the $\underline{H}$ odrick-Prescott filter. Differing from our study, these were based on annual data. Baxter and King (1999), show that their BK bandpass filter is to be preferred for quarterly data. The most compelling reason is the fact that the BK filter also removes the higher frequency irregular variation in the series, something which is not accounted for by the HP filter. The latter can therefore be regarded as the high-pass part of the BK bandpass 
filter. Whereas such irregular short run variation is a less prominent issue in annual data, its removal is an important feature for quarterly data.

After the extraction of the cyclical component, we determine the contraction and expansion periods. Periods during which a decline in the cyclical component is observed, are categorized as contractions. Periods with an increase, in turn, are categorized as expansions. We include this dichotomy in our analyses by means of a 1/0 dummy variable (see Lamey et al. 2007 for a similar practice):

$$
\text { If } G D P_{t}^{C}-G D P_{t-1}^{C}<0 \text { then Contraction }{ }_{t}=1 \text {; else }=0
$$

All months within a quarter which is marked as a contraction will show a value of 1 for the Contraction dummy variable. The original GDP series, the BK-filtered cyclical component and the associated contraction and expansion periods are depicted in figure 2 . The black line depicts the original GDP series, with values on the left axis. The dotted grey line gives the cyclical component, with values on the right axis. Finally, grey zones represent contractions, white zones expansions.

Figure 2. GDP, BK-filtered GDP cyclical component and contraction and expansion periods

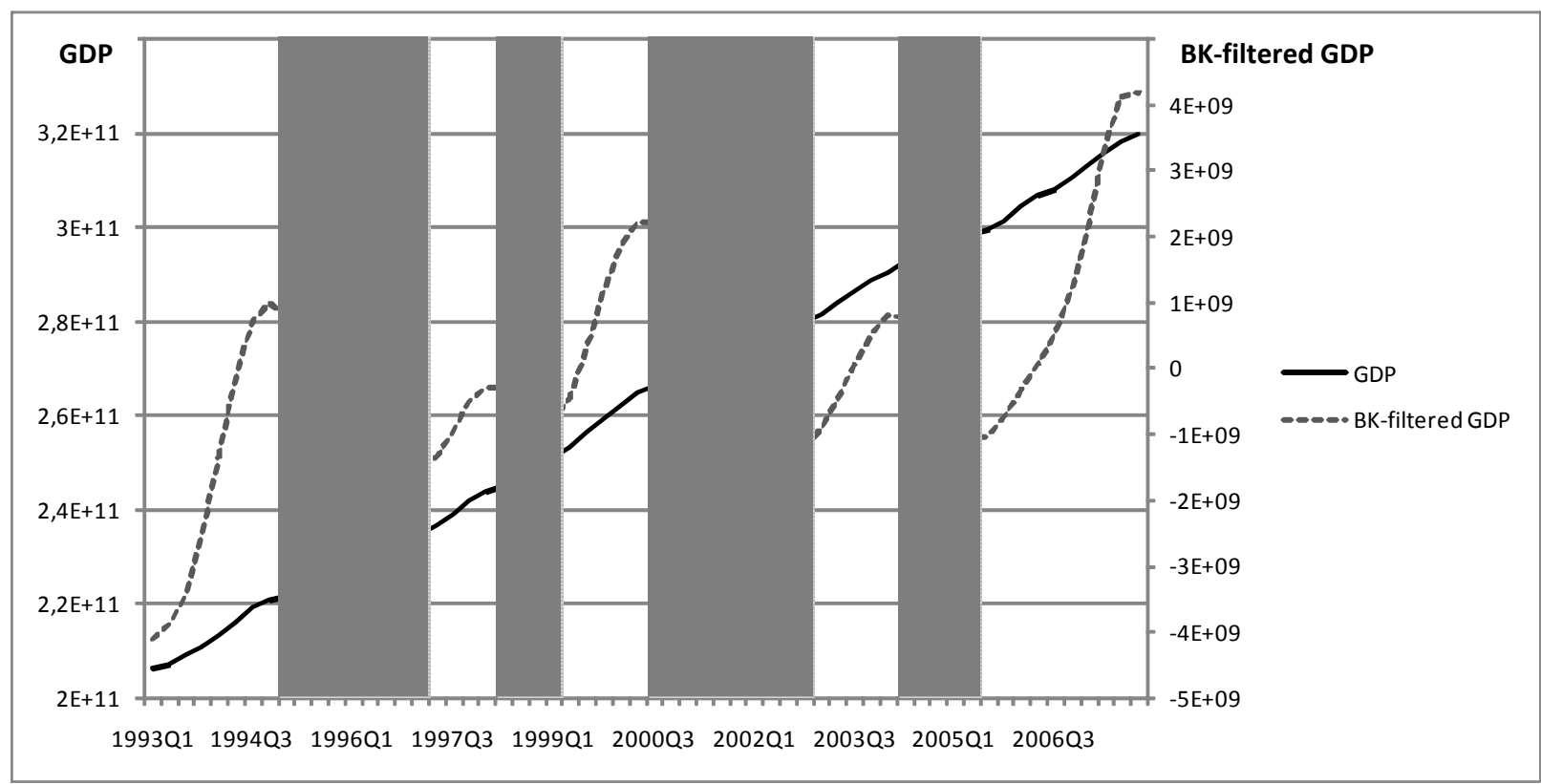




\section{Assessing the impact of the business cycle on advertising and pricing effectiveness}

When assessing the impact of the business cycle on advertising and pricing effectiveness, we face the following model requirements. First, we want to make abstraction of levels of expenditures, enabling us to draw conclusions across different types of brands and categories. Second, we allow the response parameters to vary across brands. Third, the performance of brands may be interrelated within a category, and hence we need to specify a full error covariance structure for each category. Finally, we need to accommodate the effects of moderating variables, preferably in a simultaneous estimation step for maximal statistical efficiency.

In line with previous research (e.g. Naik and Raman, 1998; Hanssens et al, 2001) we start from the following partial adjustment sales model:

$$
\begin{aligned}
\ln \text { Sal }_{t}^{c b}=\beta_{0}^{c b} & +\beta_{1}^{c b} \text { Contraction }_{t}+\beta_{2}^{c b} \ln \text { Adv }_{t}^{c b}+\beta_{3}^{c b} \ln \text { Price }_{t}^{c b}+\beta_{4}^{c b} \text { Trend }_{t} \\
& +\lambda^{c b} \ln \text { Sal }_{t-1}^{c b}+\varepsilon_{t}^{c b}
\end{aligned}
$$

in which $\ln \mathrm{Sal}_{t}^{c b}$ is the natural logarithm of the volume sales of brand $\mathrm{b}\left(\mathrm{b}=1 \ldots \mathrm{B}_{\mathrm{c}}\right)$ in category $\mathrm{c}$ $(\mathrm{c}=1 \ldots \mathrm{C})$ in month $\mathrm{t}(\mathrm{t}=1 \ldots \mathrm{T})$. Contraction ${ }_{t}$ is a dummy variable equaling 1 when the economy is in a contraction; 0 otherwise. $\ln A d v_{t}^{c b}$ is the natural logarithm of the advertising expenditures of brand b, whereas $\ln$ Price $t_{t}^{c b}$ is the natural logarithm of the price of that brand at time t. Finally, we account for the effect of possible other, trending, factors by including a deterministic trend Trend $_{t}$ (see e.g. Dekimpe and Hanssens 1995 for a similar practice) and allow for carry-over effects by including the lagged dependent variable as explanation variable. Since we specify the variables in natural logarithms, we can make abstraction of the actual level of the investments in our interpretations, as the parameter estimates represent the respective elasticities.

To account for the cyclical sensitivity of the marketing mix variables' effectiveness, we next introduce two interaction effects: Contraction ${ }_{t} * \ln$ Adv $_{t}^{c b}$ and Contraction $_{t} * \ln$ Price $_{t}^{c b}$. We also investigate to what extent the long run effectiveness of these instruments may vary across expansions and contractions by including Contraction $_{t} * \ln \mathrm{Sal}_{t-1}^{c b}$. Finally, by means of the Trend $_{t}$ we control for gradually changing factors which are not included in our model. As some 
of these factors may evolve differently because of changing overall economic conditions, we also

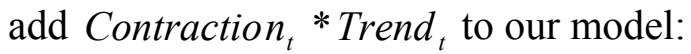

$$
\begin{aligned}
\ln \text { Sal }_{t}^{c b}=\beta_{0}^{c b} & +\beta_{1}^{c b} \text { Contraction }_{t}+\beta_{2}^{c b} \ln \text { Adv }_{t}^{c b}+\beta_{3}^{c b} \ln \text { Price }_{t}^{c b}+\beta_{4}^{c b} \text { Trend }_{t} \\
& +\beta_{5}^{c b} \text { Contraction }_{t} * \ln \text { Adv }_{t}^{c b}+\beta_{6}^{c b} \text { Contraction }_{t} * \ln \text { Price }_{t}^{c b} \\
& +\beta_{7}^{c b} \text { Contraction }_{t} * \text { Trend }_{t} \\
& +\lambda_{1}^{c b} \ln \text { Sal }_{t-1}^{c b}+\lambda_{2}^{c b} \text { Contraction }_{t} * \ln \text { Sal }_{t-1}^{c b}+\varepsilon_{t}^{c b}
\end{aligned}
$$

As sales evolutions of brands within a category may be correlated, we assume that the error vectors $\boldsymbol{\varepsilon}_{t}^{c}=\left(\varepsilon_{t}^{c 1}, \ldots, \varepsilon_{t}^{c B_{c}}\right)^{\prime}$ of each category follow a multivariate normal distribution, with a full variance-covariance matrix per category: $\boldsymbol{\varepsilon}_{t}^{c} \sim M V N\left(0, \boldsymbol{\Sigma}_{c}\right)$. Sales of brands in different categories, on the other hand, are assumed not to be correlated.

\section{Explaining cross-category differences}

In a final step, we relate the marketing effectiveness parameters $\beta_{i}^{c b}$ and $\lambda_{i}^{c b}$ to product involvement:

$$
\begin{aligned}
& \beta_{i}^{c b}=\bar{\beta}_{i, 0}+v_{\beta_{i}}^{c b}, \text { for } i \in[0,1,4,7] \\
& \beta_{i}^{c b}=\bar{\beta}_{i, 0}+\bar{\beta}_{i, 1} \text { Involvement }^{c}+v_{\beta_{i}}^{c b}, \text { for } i \in[2,3,5,6] \\
& \lambda_{i}^{c b}=\bar{\lambda}_{i, 0}+\bar{\lambda}_{i, 1} \text { Involvement }^{c}+v_{\lambda_{i}}^{c b}, \text { for } i \in[1,2]
\end{aligned}
$$

We mean-center the Involvement variable over the different categories, which allows us to formulate conclusions relative to the average category. Unobserved drivers of model parameters may cause the error terms in (5), (6) and (7) to be correlated as well, so we assume that they follow a multivariate normal distribution, with a full variance-covariance matrix per brand: $\left(\mathbf{v}_{\beta}^{c b^{\prime}}, \mathbf{v}_{\lambda}^{c b \prime}\right)^{\prime} \sim \operatorname{MVN}(0, \mathbf{\Omega})$.

We estimate model (4)-(7) with Bayesian techniques, i.e., Gibbs sampling. The benefit of this approach over classical approaches is that, at the same time, (i) it can more easily account for brand heterogeneity, as well as (ii) intra-category correlations (e.g. Rossi et al., 2005) and (iii) it estimates the moderator effects simultaneously with the other parameters rather than in a two-step approach. An overview of this procedure is given in appendix B. 


\section{Assessing long run performance}

Based on our estimations, we analyze the long run effects of both advertising and price, and how they may vary across the business cycle. Derived from our partial adjustment sales model specified in (4), we can define the long run effects as (e.g. Hanssens et al, 2001):

$$
\beta_{a d v, L R}^{c b}=\frac{\beta_{2}^{c b}}{1-\lambda_{1}^{c b}} \quad \text { and } \quad \beta_{p r i c e, L R}^{c b}=\frac{\beta_{3}^{c b}}{1-\lambda_{1}^{c b}} \quad \text { during expansions }
$$

and

$$
\beta_{a d v, L R}^{c b^{*}}=\frac{\beta_{2}^{c b}+\beta_{5}^{c b}}{1-\left(\lambda_{1}^{c b}+\lambda_{2}^{c b}\right)} \quad \text { and } \quad \beta_{p r i c e, L R}^{c b^{*}}=\frac{\beta_{3}^{c b}+\beta_{6}^{c b}}{1-\left(\lambda_{1}^{c b}+\lambda_{2}^{c b}\right)} \quad \text { during contractions. }
$$

Significantly different short run and carry over effects during contractions versus expansions do not immediately imply significantly different long run effects. Both short run effectiveness and carry-over are estimated values, each with a confidence interval, possibly with opposing effects on the ratio. Their combined effect will hence depend on the relative sizes of these intervals and on the correlations. In our Bayesian estimation procedure, we therefore also draw both long run advertising and price effectiveness, as well as the change in both due to economic downturns. This allows us to calculate in a direct way confidence intervals for these long run effects, as well as for their differences between expansions and contractions.

\section{Data}

Monthly volume sales data for 37 mature CPG categories in the United Kingdom (19932007) were provided by TNS UK. In each category, we selected the top 5 branded products which were present in the market for at least $95 \%$ of the time. Thus, our time series for the individual brands are sufficiently long to cover four business cycles (e.g. Deleersnyder et al, 2004). In total, we were able to include 163 brands in 37 markets in our sample. An overview of the included categories is given in table 2 . 
Table 2. Overview of included product categories

\begin{tabular}{lcl}
\hline Product Class & Number of Categories & Examples \\
\hline Food & 15 & Artificial sweeteners, Breakfast cereals, Butter, Tinned fruits, \\
Drinks & 7 & Fruit juices and drinks, Mineral water, Softdrinks, Tea \\
Toiletries & 8 & Bath additives, Dentifrice, Deodorants, Shampoo \\
Household Products & 7 & $\begin{array}{l}\text { Household cleaner, Machine wash products, Toilet Tissues, Washing } \\
\text { up products, }\end{array}$ \\
\hline
\end{tabular}

Table 3 provides a set of summary statistics on the relative sizes of the brands, the evolution of their market share over the 15-year period, as well as the combined market share within the category of the included brands. Although we consistently focus on the five largest brands within each category, strong variability can be found both in the average brand market share over this period and in the market share evolution. The included brands, moreover, account for substantially different combined shares.

Table 3. Market share statistics

\begin{tabular}{lcr}
\hline & Mean & Spread \\
\hline Average brand market share 1993-2007 & 0.107 & $0.005-0.699$ \\
Average brand market share evolution 1993-2007 (over the 15 years) & -0.001 & $-0.236-0.479$ \\
Average cumulative market share per category 1993-2007 & 0.471 & $0.101-0.911$ \\
\hline
\end{tabular}

The necessary price information on these brands was also obtained from TNS UK. These monthly sales and price data are subsequently combined with advertising data that were purchased from NielsenMedia UK. These data cover all advertising expenditures by the individual brands we consider, aggregated over Television, Print media, Outdoor, Cinema, Radio en Direct mail.

We use data on real GDP as a proxy for the general economic activity. The cyclical component of the GDP has proven to be a good indicator of the overall economic cycle, as it integrates business cycles fluctuations across many sectors (Stock and Watson, 1999). GDP data, expressed in constant prices, were obtained from the OECD. All marketing mix series are inflation-adjusted by means of the Consumer Price Index, which was also obtained from the OECD. 
Finally, information on product category characteristics (in particular, Involvement) was obtained through a large-scale consumer survey (see e.g. Steenkamp et al., 2007 for an in-depth discussion). Involvement was defined in the spirit of Laurent and Kapferer (1985), by including references to perceived risk and social symbolism of the category, and was measured on a fivepoint scale. After mean-centering, values range between -0.355 and 0.358 .

Companies have been shown to adjust their marketing investments in reaction to business cycle changes (e.g. Deleersnyder et al., 2009). To obtain insights in the extent to which the brands in our sample adjust their advertising and prices in a reaction to economic contractions, we extract the cyclical components of their advertising and price series by applying the BaxterKing band-pass filter. These cyclical components are subsequently regressed on the contraction dummies. The business-cycle filter, however, may induce serial correlation (Engle, 1974). We therefore allow for an autoregressive error term when needed, based on the BIC (for similar practice see e.g. Lamey et al., 2007; Deleersnyder et al., 2009). The results are shown in table 4.

Table 4. Impact of contractions on marketing mix decisions

\begin{tabular}{lccc}
\hline & Increase* $^{*}$ & Decrease* $^{*}$ & No Change \\
\hline Advertising & 19 & 28 & 116 \\
Price & 25 & 14 & 124 \\
\hline *Significant changes at 0.10 level two-sided test. & 25
\end{tabular}

*Significant changes at the 0.10 level. two-sided test.

Changes in marketing investments appear rather limited for the brands in our sample. Among those brands that do change their investments, we observe large variation in the decisions. Nevertheles, there are some indications of the earlier reported tendencies to decrease advertising budgets (Deleersnyder et al, 2009) and increase prices (e.g. Backus and Kehoe, 1992; Rotemberg and Saloner, 1986; Rotemberg and Woodford, 1999; Deleersnyder et al., 2004). Of the 74 brands that thus significantly change their investments in at least one of the marketing mix instruments, only 12 modify their expenditures on both instruments. To test for overall significance of the changes, we applied the method of added Z's (Rosenthal, 1991). These tests showed that prices are not significantly increased $(\mathrm{p}=0.14$, one-sided), whereas there are indications that advertising expenditures are reduced $(p<0.10$, one-sided). 


\section{Empirical results}

The coefficient estimates are presented in table 5. They show the $95 \%$ posterior density intervals for the estimates. These are printed in bold if zero is not included in the interval.

Table 5. Parameter estimates

\begin{tabular}{|c|c|c|c|c|c|}
\hline & & hypothesis & $2.5^{\text {th }}$ percentile & median & $97.5^{\text {th }}$ percentile \\
\hline Intercept & $\bar{\beta}_{0,0}$ & & -0.010 & 0.037 & 0.089 \\
\hline Contraction & $\bar{\beta}_{1,0}$ & - & -0.019 & 0.001 & 0.026 \\
\hline Advertising & $\bar{\beta}_{2,0}$ & + & 0.002 & 0.003 & 0.005 \\
\hline x Involvement & $\bar{\beta}_{2,1}$ & - & -0.015 & -0.008 & -0.000 \\
\hline Advertising*Contraction & $\bar{\beta}_{5,0}$ & $?$ & -0.001 & 0.000 & 0.001 \\
\hline x Involvement & $\bar{\beta}_{5,1}$ & $?$ & -0.008 & -0.000 & 0.007 \\
\hline Price & $\bar{\beta}_{3,0}$ & - & -1.207 & -1.075 & -0.927 \\
\hline x Involvement & $\bar{\beta}_{3,1}$ & + & -0.795 & 0.004 & 0.872 \\
\hline Price*Contraction & $\bar{\beta}_{6,0}$ & - & -0.242 & -0.148 & -0.060 \\
\hline x Involvement & $\bar{\beta}_{6,1}$ & + & 0.173 & 0.590 & 0.951 \\
\hline Carry-over & $\bar{\lambda}_{1,0}$ & + & 0.504 & 0.535 & 0.564 \\
\hline$x$ Involvement & $\bar{\lambda}_{1,1}$ & - & -0.379 & -0.203 & -0.035 \\
\hline Carry-over ${ }^{*}$ Contraction & $\bar{\lambda}_{2,0}$ & - & -0.074 & -0.053 & -0.032 \\
\hline x Involvement & $\bar{\lambda}_{2,1}$ & + & -0.043 & 0.042 & 0.133 \\
\hline Trend & $\bar{\beta}_{4,0}$ & $?$ & -0.002 & -0.001 & -0.000 \\
\hline Trend ${ }^{*}$ Contraction & $\bar{\beta}_{7,0}$ & $?$ & -0.000 & 0.000 & 0.001 \\
\hline
\end{tabular}

\section{Cyclical sensitivity of sales}

Economic downturns as such do not seem to impact sales of the included brands. This may be a consequence of the fact that most of these CPG categories can be considered necessities. Purchases of such products are not likely to, or cannot, be postponed until the economic conditions improve. 


\section{Short run marketing effectiveness}

Advertising. Consistent with Lodish et al. (1995) and Ataman et al. (2009), advertising elasticities are found to be particularly small for these types of mature consumer goods $\left(\bar{\beta}_{2,0}=\right.$ $0.003)$. As we hypothesized, higher involvement products show significantly smaller advertising elasticities $\left(\bar{\beta}_{2,1}=-0.008\right)$. Although advertising will be processed more thoroughly, the more elaborated decisions processes for higher involvement products lower the relative weight and hence the effect on the final outcome.

Price. As could be expected from previous literature (e.g. Bijmolt et al., 2004; Ataman et al., 2009), price elasticities are found to be much larger compared to advertising elasticities ( $\bar{\beta}_{3,0}$ $=-1.075)$. Contrary to our predictions, higher involvement product categories do not show smaller price elasticities.

\section{Cyclical sensitivity of marketing effectiveness}

Advertising. Business cycles do not seem to affect the short run effectiveness of advertising. Notwithstanding arguments supporting both an increase and a decrease of advertising effectiveness during economic contractions, no significant effects could be found.

Price. As we expected, price sensitivity increases during contractions $\left(\bar{\beta}_{6,0}=-0.148\right)$. This effect, however, will be mitigated when the involvement with the product category is higher $\left(\bar{\beta}_{6,1}=0.590\right)$. Price sensitivity does increase, but the effects will be stronger in those categories were decisions are usually based on simple heuristics like e.g. price. More involvement and hence more in-depth decision making will smooth the effect of price on actual sales.

\section{Long run marketing effectiveness}

Long run effectiveness, as (8) and (9) show, depends on the short run effectiveness of the marketing mix instruments and the carry-over effect of sales. We therefore first report the estimation results for carry-over.

Carry-over. Estimated carry-over effects are rather small $\left(\bar{\lambda}_{1,0}=0.535\right)$. The effect, however, will be stronger for products for which consumers rely on simple effort-reducing heuristics like e.g. the last brand purchased $\left(\bar{\lambda}_{1,1}=-0.203\right)$. Carry-over effects, in addition, are 
significantly smaller during economic downturns $\left(\bar{\lambda}_{2,0}=-0.051\right)$, as consumers are likely to show stronger switching behavior and less consistent buying patterns for national brands during contractions (e.g. Chance and French, 1972; Block, 1979; Wakefield and Inman, 1993. No significant differences in the impact of economic downturns on carry-over could be found between high and low involvement products.

The resulting estimated values for the long run effectiveness of Advertising and Price are reported in table 6 . These are the estimates for an average product, implying a zero effect of Involvement.

Table 6. Long run advertising and price effectiveness for an average product

\begin{tabular}{lccc}
\hline & $\mathbf{2 . 5}^{\text {th }}$ percentile & median & $\mathbf{9 7 . 5}^{\text {th }}$ percentile \\
\hline Long run Advertising effectiveness Expansion & 0.005 & $\mathbf{0 . 0 0 7}$ & 0.010 \\
$\Delta$ Long run Advertising effectiveness $\beta_{a d v, L R}-\beta_{a d v, L R}^{*}$ & -0.002 & 0.001 & 0.003 \\
& & & -2.018 \\
Long run Price effectiveness Expansion & -2.617 & $\mathbf{- 2 . 3 0 6}$ & 0.193 \\
$\Delta$ Long run Price effectiveness $\beta_{\text {price }, L R}-\beta_{\text {price }, L R}^{*}$ & -0.107 & 0.054 & \\
\hline
\end{tabular}

Long run effects are about double the size of short run effects (Advertising: 0.007 vs 0.003; Price: -2.306 vs -1.075). Although we find decreases in long run advertising effects $\left(\beta_{a d v, L R}-\beta_{a d v, L R}^{*}=0.001\right)$ and increases in long run price effects $\left(\beta_{p r i c e, L R}-\beta_{p r i c e, L R}^{*}=0.054\right)$ during contractions versus expansions, none of these changes is significant. Whereas the tactical implications of marketing mix decisions are hence altered by the position in the business cycle, long run strategic implications will stay fairly constant.

\section{Discussion}

\section{Summary}

Although marketing effectiveness has been the subject of a wide stream of research, to the best of our knowledge, no study has investigated in a systematic way how general economic conditions may affect this effectiveness. We therefore investigated how advertising and price 
elasticities evolve across the business cycle, i.e. how they differ in contractions vs expansions. Further, we examined to what extent evolutions may be different for different levels of product involvement. Analyses were based on 163 branded products in 37 mature CPG categories in the UK, and this for a period of 15 years. We combined (i) monthly national sales data, (ii) monthly advertising data, (iii) data on economic activity, and (iv) consumer survey data.

Most of the hypothesized effects were supported, as was shown in table 5. During contractions, consumers become more price sensitive. In addition, spending patterns will be less consistent, implying smaller brand loyalty. Advertising elasticities, however, do not seem to be affected by economic downturns. Such downturns, in addition, do not show a direct effect on the sales of the included products. As these are often purchased products which could be categorized as necessities, postponing purchases until the economy recovers is hence not an option. Finally, although short run effectiveness of price differs between expansions and contractions, the long run effectiveness of both advertising and price is not altered by differences in the general economic conditions.

\section{Managerial implications}

Firms are under increasing pressure to increase both the accountability and the effectiveness of their marketing investments. Our findings can help managers in choosing the right strategies when deciding on marketing investments across the business cycle.

One of the central questions marketing managers have to decide on, is how to allocate their budgets over price reductions (by lowering the margins) and advertising actions. To provide answers to this question, we base ourselves on the framework developed by Dorfman and Steiner (1954). In their work, the authors argue that marketing budgets should be allocated relative to the ratios of the respective elasticities. More effective instruments, i.e. those showing higher elasticities, thus receive larger parts of the overall marketing budget. As Sethuraman and Tellis (1991), we therefore report the price/advertising elasticity ratios in expansion and contractions for products with different levels of involvement. High and Low Involvement are defined as one standard deviation above and below the Average level, Very High and Very Low as two standard deviations above and below the Average level. The results are summarized in table 7 . The changes in the ratios provide us with an indication how relative allocation should be altered to improve short run performance. 
Overall, price/advertising ratios are remarkably high. However, the product categories under investigation are all well established mature CPG categories. For such products, advertising has been proven to be much less effective relative to newer products, whereas price does play a more important role in purchase decision making, leading to higher ratios relative to newer products (Sethuraman and Tellis, 1991). These indicate that, for such mature products, firms can gain more by reducing their prices compared to investing in advertising campaigns. The extreme values for the High Involvement categories are a consequence of advertising showing very limited final effects on sales for such products (cfr. Ataman et al., 2009).

Table 7. Price-Advertising elasticity ratios

\begin{tabular}{lccc}
\hline & Expansion & Contraction & \% Change \\
\hline Very Low Involvement & 185.491 & 246.601 & $+33 \%$ \\
Low Involvement & 244.444 & 301.539 & $+23 \%$ \\
Average Involvement & 358.333 & 407.667 & $+14 \%$ \\
High Involvement & 670.919 & 698.953 & $+4 \%$ \\
Very High Involvement & 5255.182 & 4970.846 & $-5 \%$ \\
\hline
\end{tabular}

In general, firms are encouraged to increase their price efforts relative to advertising in the short run. For products showing average involvement, the short run price/advertising elasticity ratio increases with $14 \%$ during contractions. This is a consequence of the increased price sensitivity during contractions, with advertising sensitivity remaining stable over the business cycle. Sales gains are hence better achieved by price reductions than by advertising increases.

For lower involvement categories, the change in recommended relative budget allocation will be even stronger. Although advertising is more effective for these products, resulting in lower overall ratios, price sensitivity will increase much stronger during contractions. As consumers feel the pressure on their reduced budgets, the pricing heuristic will become much more prominent in their decisions for low-involvement products. A clear shift in marketing budgets from advertising to price reductions is therefore warranted.

However, such shifts from advertising to price efforts are not recommended for all product types. For very high involvement product categories, the ratio shows an opposite evolution, with a relative change of the ratio with $-5 \%$ towards advertising budgets. This change is not so much a consequence of changes in advertising effectiveness. Advertising elasticities are 
extremely small for such categories, as is reflected in the very high values for the ratios. Such categories, however, are characterized by decreases of price sensitivity during contractions. Although consumers' budgets are tighter during contractions, pricing may become even less important in relative terms compared to expansions. Reducing the risk of buying a wrong product is more than ever a dominant concern in uncertain times, and consumers will consequently engage in even more profound information gathering and decision making, in which price will receive less weight relative to more functional aspects of the product.

An important remaining question, however, is how these findings can be reconciled with observations that companies spending relatively more on advertising during economic downturns have better financial performance (Frankenberger \& Graham, 2003; Srinivasan et al., 2005; Deleersnyder et al., 2009; Srinivasan and Lilien, 2009). Shifting budgets from advertising to price reductions appears a recommended tactical decision to increase sales in the short run. Long run effects, however, are not altered by the general economic conditions. Consequently, at the strategic level, based on long run ratios, relative budget allocation should not be modified. Companies staying closer to these long run ratios by not cutting back on relative advertising expenditures may hence show better financial performance, as stock prices are hypothesized to incorporate all long run performance information of the company, an effect which may be enhanced by stronger deviations by competing companies from their optimal relative allocation. Cutting back too much on advertising may damage the brand in the long run, an effect which can be exacerbated by a lowering price image among customers when spending too much on price reductions. In addition, as advertising effectiveness as such does not change over the business cycle, extra investments in advertising can be expected to increase the company's results. Managers should consequently decide to what extent they consider marketing investments short run tactical means versus long run strategic investments. In the latter case, permanent evaluation and adjustment of the relative allocation of means is not needed. If, on the other hand, short run sales gains are the target, then a good understanding of the general economic situation in combination with changes in relative allocation becomes warranted. 


\section{Directions for future research}

In this work, we analyzed advertising and price elasticities for a wide set of products and categories. We thereby focused on the 5 most important branded products per category, provided that they were on the market for at least $95 \%$ of the time. As such, we could expand our dataset in four ways: (i) allow for smaller brands, (ii) allow for private labels, (iii) investigate less mature categories, and (iv) examine durables.

First, we could enlarge our dataset by also including smaller brands in our analyses. However, in order to cover multiple business cycles and not to base our findings on the artifacts of just one cycle, brands have to be on the market long enough. As smaller brands may have more difficulties in complying with this condition, we opted to focus ourselves to the top 5 . Further research in this direction hence appears warranted.

Second, we only focused on branded products. Examining to what extent marketing mix effectiveness varies over the business cycle for private labels makes up an interesting avenue for future research, especially given their remarkable and persistent market share gains during contractions (Lamey et al., 2007).

Third, our analyses are based on mature CPG categories. Such products are characterized by very small advertising elasticities (e.g. Sethuraman and Tellis, 1991). Less mature categories, on the other hand, can be expected to show stronger advertising sensitivity. In addition, this sensitivity may also vary more with the overall economic sentiment. Future research could hence include such products.

Finally, the products in our dataset are mainly every day necessities. Purchases cannot really be postponed until the economy recovers. This, on the other hand, is not the case for durables. Consumers can and do wait until the economic conditions improve and the uncertainty diminishes (Deleersnyder et al., 2004). This could result in even stronger business cycle effects on marketing mix effectiveness. A deeper investigation into this issue is hence called for. 


\section{References}

AdAge (2009). When Will This End? February 16.

Allenby, G.M., Jen, L. \& Leone, R.P. (1996). Economic Trends and Being Trendy: The Influence of Consumer Confidence on Retail Fashion Sales. Journal of Business and Economic Statistics, Vol 14 (1). pp 103-111.

Ang, S.H., Leong, S.M. \& Kotler, P. (2000). The Asian Apocalypse: Crisis Marketing for Consumers and Businesses. Long Range Planning, Vol 33. pp 97-119.

Assael, H. (1998). Consumer Behavior and Marketing Action, $6^{\text {th }}$ Edition. Cincinatti, OH. SouthWestern College Publishing

Assmus, G., Farley, J.U. \& Lehmann, D.R. (1984). How advertising affects sales: meta-analysis of econometric results. Journal of Marketing Research, Vol 21 (February). pp 65-74.

Ataman, M.B., Van Heerde, H.J. \& Mela, C.F. (2009). The Long-term Effect of Marketing Strategy on Brand Sales. Under review.

Axarloglou, K. (2003). The Cyclicality of New Product Introductions. Journal of Business, Vol 76 (January). pp 29-48.

Backus, D.K. \& Kehoe, P.J. (1992). International Evidence on the Historical Properties of Business Cycles. American Economic Review, Vol 82 (4). pp 864-888

Baxter, M. \& King, R.G. (1999). Measuring Business Cycles: Approximate Band-Pass Filters for Economic Time Series. The Review of Economics and Statistics, Vol 81 (November). pp 575-593.

Bijmolt, T.H.A., Van Heerde, H.J. \& Pieters, R.G.M. (2005). New Empirical Generalizations on the Determinants of Price Elasticity. Journal of Marketing Research, Vol 42 (2). pp 141156.

Bloch, P.H., Sherrell, D.L. \& Ridgway, N.M. (1986). Consumer Search: An Extended Framework. Journal of Consumer Research, Vol 19 (1). pp 119-126.

Block, F.L. (1979). The Origins of Economic Disorders. Berkely, CA. University of California Press.

Burns, A.M. \& Mitchell, W.C. (1946). Measuring Business Cycles. New York. National Bureau of Economic Research.

Chance, W.A. \& French, N.D. (1972). An Exploratory Investigation of Brand Switching. Journal of Marketing Research, Vol 9 (2). pp 226-229. 
Christiano, L.J. \& Fitzgerald, T.J. (1998). The Business Cycle: It's Still a Puzzle. Economic Perspectives, Vol 22 ( $4^{\text {th }}$ quarter), Federal Reserve Bank of Chicago. pp 56-83.

Clarke, D.G. (1976). Econometric Measurement of the Duration of Advertising Effect on Sales. Journal of Marketing Research, Vol 13 (4). pp 345-357.

CMO Council (2009). Marketing Outlook 2009.

Danaher, P.J., Bonfrer, A., \& Dhar, S. (2008). The Effect of Competitive Advertising Interference on Sales for Packaged Goods. Journal of Marketing Research, Vol 45 (2). pp 211-225.

Dekimpe, M.G. \& Hanssens, D. (1995). The Persistence of Marketing Effects on Sales. Marketing Science, Vol 14 (1). pp 1-21.

Deleersnyder, B., Dekimpe, M.G., Sarvary, M. \& Parker, P.M. (2004). Weathering Tight Economic Times: The Sales Evolution of Consumer Durables over the Business-Cycle. Quantitative Marketing and Economics, Vol 2 (4). pp 347-383.

Deleersnyder, B., Dekimpe, M.G., Steenkamp, J-B.E.M. \& Leeflang, P.L. (2009). The Role of National Culture in Advertising's Sensitivity to Business Cycles: An Investigation across Categories. Journal of Marketing Research, forthcoming.

Desphandé, R. (1982). The Organizational Context of Market Research Use. Journal of Marketing, Vol 46 (4). pp 91-101.

Devinney, T.M. (1990). New Products over the Business Cycle. Journal of Product Innovation Management, Vol 7. pp 261-273.

Dorfman, R. \& Steiner, P.O. (1954). Optimal Advertising and Optimal Quality. The American Economic Review, Vol 44 (5). pp 826-836.

Frankenberger, K.D. \& Graham, R.G. (2003). Should Firms Increase Advertising Expenditures During Recessions? MSI Report no 03-003. Cambridge MA. Marketing Science Institute.

Engle, R.F. (1974). Band Spectrum Regression. International Economic Review, Vol 15 (1). pp 107-128.

Estelami, H., Lehmann, D.R. \& Holden, A.C. (2001). Macro-Economic Determinants of Consumer Price Knowledge: A Meta-Analysis of Four Decades of Research. International Journal of Research in Marketing, Vol 18 (4). pp 341-355.

Granger, C.W.J. \& Hatanaka, M. (1964). Spectral Analysis of Economic Time Series. Princeton. Princeton Press.

Hanssens, D.M., editor (2009). Empirical Generalizations about Marketing Impact. Cambridge, MA. Marketing Science Institute, Relevant Knowledge Series. 
Hanssens, D.M., Parsons, L.J. \& Schultz, R.L. (2001). Market Response Models. International Series in Quantitative Marketing. Dordrecht. Kluwer Academic Publishers.

Hawkins, S.A. \& Hoch, S.J. (1992). Low-Involvement Learning: Memory Without Evaluation. Journal of Consumer Research, Vol 19 (2). pp 212-225.

Hoyer, W.D. (1984). An Examination of Consumer Decision Making for a Common Repeat Purchase Product. Journal of Consumer Research, Vol 11 (3). pp 822-829.

Hoyer, W.D. \& Brown, S.P. (1990). Effects of Brand Awareness on Choice for a Common, Repeat-Purchase Product. Journal of Consumer Research, Vol 17 (2). pp 141-148.

Jeuland, A.P. (1979). Brand Choice Inertia as One Aspect of Brand Loyalty. Management Science, Vol 25 (7). pp 671-682.

Kamakura, W.A. \& Gessner, G. (1986). Consumer Sentiment and Buying Intentions Revisited: A Comparison of Predictive Usefulness. Journal of Economic Psychology, Vol 7 (2). pp 197220 .

Katona, G. (1975). Psychological Economics, New York: Elsevier Scientific Publishing Co.

Keller, K.L. (1993). Conceptualizing, Measuring and Managing Customer-Based Brand Equity. Journal of Marketing, Vol 57 (1). pp 1-22.

Krugman, H.E. (1965). The Impact of Television Advertising: Learning without Involvement. Public Opinion Quarterly, Vol 29. pp 349-356.

Lambin, J-J, Naert, P. \& Bultez, A. (1975). What is the Real Impact of Advertising? Harvard Business Review, Vol 53 (may-june). pp 139 -147.

Lamey, L., Deleersnyder, B., Dekimpe, M.G. \& Steenkamp, J-B.E.M. (2007). How Business Cycles Contribute to Private-Label Success: Evidence from the United States and Europe. Journal of Marketing, Vol 71 (1). pp 1-15.

Laurent, G. \& Kapferer, J.N. (1985). Measuring Consumer Involvement Profiles. Journal of Marketing Research, Vol 22 (1). pp 41-53.

Lodish, L.M., Abraham, M., Kalmenson, S., Livelsberger, J., Lubetkin, B., Richardson, B. \& Stevens, M.E. (1995). How T.V. advertising works: A meta-analysis of 389 real world split cable T.V. advertising experiments. Journal of Marketing Research. Vol 32 (may 1995), pp 125-139.

Marketing Science Institute (2008). 2008-2010 Research Priorities. Cambridge, MA. Marketing Science Institute.

McKinsey (2009). The Crisis: A New Era in Management. McKinsey Quarterly, 2009 (1). 
Naik, P.A. \& Raman, K. (2003). Understanding the Impact of Synergy in Multimedia Communications. Journal of Marketing Research, Vol 40. pp 375-388.

Newman, J.W. \& Staelin, R. (1972). Prepurchase Information Seeking for Cars and Major Household Appliances. Journal of Marketing Research, Vol 9 (3). pp 249-257.

Park, W.C. \& Mittal, B. (1985). A Theory of Involvement in Consumer Behaviour: Problems and Issues. In: Sheth, J.N., eds. Research in Consumer Behaviour. Greenwich, CT. JAI Press.

Petty, R.E., Cacioppo, J.T. \& Schumann, D. (1983). Central and Peripheral Routes to Advertising Effectiveness: The Moderating Role of Involvement. Journal of Consumer Research, Vol 10 (2). pp 135-146.

Punj, G.N. \& Staelin, R. (1983). A Model of Consumer Information Search Behavior for New Automobiles. Journal of Consumer Research, Vol 9 (4). pp 366-380.

Quelch, J.A. \& Harding, D. (1996). Brands Versus Private Labels: Fighting to Win. Harvard Business Review, Vol 37 (Winter). pp 99-109.

Quelch, J.A. (2008). Family First in Tough Marketing Times. The Financial Times, February 17.

Rossi, P.E., Allenby, G.M. \& McCulloch, R. (2005). Bayesian Statistics and Marketing. Chichester, West Sussex. John Wiley and Sons ltd.

Rotemberg, J.J. \& Saloner, G. (1986). The Supergame-Theoretic Model of Price Wars During Booms. American Economic Review, Vol 76 (3). pp 390-407.

Rotemberg, J.J. \& Woodford, M. (1999). The Cyclical Behavior of Prices and Costs. In: Taylor, J. \& Woodford, M. eds. Handbook of Macroeconomics. Amsterdam: Elsevier Science BV. pp 1051-1135.

Sethuraman, R. \& Tellis, G.J. (1991). An Analysis of the Trade-off between Advertising and Price Discounting. Journal of Marketing Research, Vol 28 (2). pp 160-174.

Sheth, J.N \& Venkatesan, M. (1968). Risk-Reduction Processes in Repetitive Consumer Behavior. Journal of Marketing Research, Vol 5 (3). pp 307-310.

Simon, H. (1979). Dynamics of Price Elasticity and Brand Life Cycles: An Empirical Study. Journal of Marketing Research, Vol 16 (4). pp 439-452.

Srinivasan, R., Rangaswamy, A. \& Lilien, G. (2005). Turning Adversity into Advantage: Does Proactive Marketing During a Recession Pay Off? International Journal of Research in Marketing, Vol 22 (june). pp 109-125.

Srinivasan, R. \& Lilien, G. (2009). An Empirical Investigation of R\&D, Advertising and Firm Performance in Recessions. Working Paper. 
Srivastava, R.K., Shervani, T.A. \& Fahey, L. (1999). Marketing, Business Processes and Shareholder Value: An Organizationally Embedded View of Marketing Activities and the Discipline of Marketing. Journal of Marketing, Vol 63 (Special Issue 1999). pp 168-179.

Stock, J.H. \& Watson, M.W. (1999). Business Cycle Fluctuations in US Macroeconomic Time Series. In: Taylor, J. \& Woodford, M. eds. Handbook of Macroeconomics. Amsterdam: Elsevier Science BV. pp 3-64.

Tellis, G.J. (1988). The Price Elasticity of Selective Demand: A Meta-Analysis of Econometric Models of Sales. Journal of Marketing Research, Vol 25 (4). pp 331-341.

Tellis, G.J \& Ambler, T., eds (2007). The SAGE Handbook of Advertising. Sage Publications ltd, Thousand Oaks.

Tellis, G.J. \& Franses, P.H. (2006). Optimal Data Interval for Estimating Advertising Response. Marketing Science, Vol 25 (3). pp 217-229.

The Financial Times (2008). Marketing Budget Cuts Predict to Deepen. July 13.

Tversky, A. \& Kahneman, D. (1974). Judgement under Uncertainty: Heuristics and Biases. Science, Vol 185. pp 1124-1131

Vakratsas, D. \& Ambler, T. (1999). How Advertising Works: What Do We Really Know? Journal of Marketing, Vol 63(1). pp 26-43.

Van Trijp, H.C.M., Hoyer, W.D. \& Inman, J.J. (1996). Why Switch? Product Category-Level Explanations for True Variety-Seeking Behavior. Journal of Marketing Research, Vol 33 (3). pp 281-292.

Vilasosu, J.R. (1997). The Relationship Between Cash-Flow and Investment in the United States at Business Cycle Frequencies. Applied Economics, Vol 29 (10). pp 1283-1293.

Wakefield, K.L. \& Inman, J.J. (1993). Who Are the Price Vigilantes? An Investigation of Differentiating Characteristics Influencing Price Information Processing. Journal of Retailing, Vol 69 (Autumn). pp 216-233.

Warrington, P. \& Shim, S. (2000). An Empirical Investigation of the Relationship between Product Involvement and Brand Commitment. Psychology and Marketing, Vol 17 (9). pp 761-782. 


\section{Appendix A: Band-Pass filter weights for Baxter-King filter}

1. Band-Pass filter weights for quarterly data

\begin{tabular}{cr}
\hline Weights & Value \\
\hline $\mathrm{a}_{0}$ & 0.2777 \\
$\mathrm{a}_{1}=\mathrm{a}_{-1}$ & 0.2204 \\
$\mathrm{a}_{2}=\mathrm{a}_{-2}$ & 0.0838 \\
$\mathrm{a}_{3}=\mathrm{a}_{-}$ & -0.0521 \\
$\mathrm{a}_{4}=\mathrm{a}_{-}$ & -0.1184 \\
$\mathrm{a}_{5}=\mathrm{a}_{-5}$ & -0.1012 \\
$\mathrm{a}_{6}=\mathrm{a}_{-}$ & -0.0422 \\
$\mathrm{a}_{7}=\mathrm{a}_{-}$ & 0.0016 \\
$\mathrm{a}_{8}=\mathrm{a}_{-8}$ & 0.0015 \\
$\mathrm{a}_{9}=\mathrm{a}_{-}$ & -0.0279 \\
$\mathrm{a}_{10}=\mathrm{a}_{-10}$ & -0.0501 \\
$\mathrm{a}_{11}=\mathrm{a}_{-11}$ & -0.0423 \\
$\mathrm{a}_{12}=\mathrm{a}_{-12}$ & -0.0119 \\
\hline
\end{tabular}

2. Band-Pass filter weights for monthly data

\begin{tabular}{|c|c|c|c|c|c|}
\hline Weights & Value & Weights & Value & Weights & Value \\
\hline $\mathrm{a}_{0}$ & 0.0925 & & & & \\
\hline$a_{1}=a_{-1}$ & 0.0903 & $a_{13}=a_{-13}$ & -0.0403 & $a_{25}=a_{-25}$ & -0.0023 \\
\hline $\mathrm{a}_{2}=\mathrm{a}_{-2}$ & 0.0838 & $\mathrm{a}_{14}=\mathrm{a}_{-14}$ & -0.0382 & $a_{26}=a_{-26}$ & -0.0057 \\
\hline$a_{3}=a_{-3}$ & 0.0734 & $\mathrm{a}_{15}=\mathrm{a}_{-15}$ & -0.0338 & $a_{27}=a_{-27}$ & -0.0093 \\
\hline $\mathrm{a}_{4}=\mathrm{a}_{-4}$ & 0.0600 & $a_{16}=a_{-16}$ & -0.0278 & $a_{28}=a_{-28}$ & -0.0126 \\
\hline $\mathrm{a}_{5}=\mathrm{a}_{-5}$ & 0.0445 & $a_{17}=a_{-17}$ & -0.0210 & $a_{29}=a_{-29}$ & -0.0152 \\
\hline$a_{6}=a_{-6}$ & 0.0279 & $a_{18}=a_{-18}$ & -0.0141 & $a_{30}=a_{-30}$ & -0.0168 \\
\hline$a_{7}=a_{-7}$ & 0.0114 & $\mathrm{a}_{19}=\mathrm{a}_{-19}$ & -0.0079 & $a_{31}=a_{-31}$ & -0.0171 \\
\hline$a_{8}=a_{-8}$ & -0.0040 & $\mathrm{a}_{20}=\mathrm{a}_{-20}$ & -0.0029 & $a_{32}=a_{-32}$ & -0.0162 \\
\hline $\mathrm{a}_{9}=\mathrm{a}_{-9}$ & -0.0174 & $\mathrm{a}_{21}=\mathrm{a}_{-21}$ & 0.0005 & $\mathrm{a}_{33}=\mathrm{a}_{-33}$ & -0.0141 \\
\hline$a_{10}=a_{-10}$ & -0.0280 & $\mathrm{a}_{22}=\mathrm{a}_{-22}$ & 0.0021 & $a_{34}=a_{-34}$ & -0.0112 \\
\hline$a_{11}=a_{-11}$ & -0.0354 & $a_{23}=a_{-23}$ & 0.0021 & $a_{1}=a_{-35}$ & -0.0077 \\
\hline$a_{12}=a_{-12}$ & -0.0395 & $\mathrm{a}_{24}=\mathrm{a}_{-24}$ & 0.0005 & $a_{36}=a_{-36}$ & -0.0040 \\
\hline
\end{tabular}




\section{Appendix B: MCMC estimation of a Hierarchical Bayes Model.}

Before describing the applied methodology, we will first briefly repeat the model specification:

Sales $\ln S a l_{t}^{c b}$ of brand $\mathrm{b}\left(\mathrm{b}=1 \ldots \mathrm{B}_{\mathrm{c}}\right)$ in category $\mathrm{c}(\mathrm{c}=1 \ldots \mathrm{C})$ at time $\mathrm{t}(\mathrm{t}=1 \ldots \mathrm{T})$ are described by the following linear model:

$$
\begin{aligned}
\ln \text { Sal }_{t}^{c b}=\beta_{0}^{c b} & +\beta_{1}^{c b} \text { Contraction }_{t}+\beta_{2}^{c b} \ln \text { Adv }_{t}^{c b}+\beta_{3}^{c b} \ln \text { Price }_{t}^{c b}+\beta_{4}^{c b} \text { Trend }_{t} \\
& +\beta_{5}^{c b} \text { Contraction }_{t} * \ln \text { Adv }_{t}^{c b}+\beta_{6}^{c b} \text { Contraction }_{t} * \ln \text { Price }_{t}^{c b} \\
& +\beta_{7}^{c b} \text { Contraction }_{t} * \text { Trend }_{t} \\
& +\lambda_{1}^{c b} \ln \text { Sal }_{t-1}^{c b}+\lambda_{2}^{c b} \text { Contraction }_{t} * \ln \text { Sal }_{t-1}^{c b}+\varepsilon_{t}^{c b}
\end{aligned}
$$

Or

$$
y_{t}^{c b}=\mathbf{x}_{\beta, t}^{c b} \boldsymbol{\beta}^{c b}+\mathbf{x}_{\lambda, t}^{c b} \lambda^{\prime} \lambda^{c b}+\varepsilon_{t}^{c b}
$$

Where

$$
\boldsymbol{\varepsilon}_{t}^{c} \sim \operatorname{MVN}\left(0, \boldsymbol{\Sigma}_{c}\right)
$$

We relate the response parameters $\boldsymbol{\beta}^{c b}$ and $\lambda^{c b}$ on a set of second stage variables:

$$
\boldsymbol{\beta}^{c b}=\mathbf{m}_{\beta}^{c b} \overline{\boldsymbol{\beta}}+\mathbf{v}_{\beta}^{c b}
$$

$$
\lambda^{c b}=\mathbf{m}_{\lambda}^{c b} \bar{\lambda}+\mathbf{v}_{\lambda}^{c b}
$$

Where

$$
\left(\mathbf{v}_{\beta}^{c b \prime}, \mathbf{v}_{\lambda}^{c b^{\prime}}\right)^{\prime} \sim \operatorname{MVN}(0, \mathbf{\Omega}) .
$$

We stack (i) the dependent variables of equation (B1) for all brands $b$ in category $c$ and time periods $t$ so that the vector of $\ln$ Sales is $\mathbf{y}^{c}=\left[y_{1}^{c 1}, y_{2}^{c 1}, \ldots, y_{T}^{c B_{c}}\right]^{\prime}$, (ii) the predictor variables $\mathbf{x}_{\beta, t}^{c b}{ }^{\prime}=\left[x_{\beta, 0, t}^{c b}, x_{\beta, 1, t}^{c b}, \ldots, x_{\beta, 6, t}^{c b}\right]$ and $\mathbf{x}_{\lambda, t}^{c b}{ }^{\prime}=\left[x_{\lambda, 1, t}^{c b}, x_{\lambda, 2, t}^{c b}\right]$, and (iii) the error terms of this equation for all brands $\mathrm{b}$ and time periods $t$ so that $\boldsymbol{\varepsilon}_{t}^{c^{\prime}}=\left[\varepsilon_{t}^{c 1}, \varepsilon_{t}^{c 2}, \ldots, \varepsilon_{t}^{c B_{c}}\right]^{\prime}$ follows a $B_{c^{-}}$-variate normal distribution with zero mean and full covariance matrix $\Sigma_{\mathbf{c}}$. 
We subsequently specify the hierarchical relations in the sales equation. We stack (i) the parameter coefficients per category and per brand across equations (B3) and (B4) and (ii) the error terms of the hierarchical equations for all brands $b$ in a similar way. We model the response parameters as follows:

$$
\left[\begin{array}{c}
\boldsymbol{\beta}^{c 1} \\
\boldsymbol{\lambda}^{c 1} \\
\boldsymbol{\beta}^{c 2} \\
\boldsymbol{\lambda}^{c 2} \\
\vdots \\
\boldsymbol{\beta}^{c B_{c}} \\
\boldsymbol{\lambda}^{c B_{c}}
\end{array}\right]=\left[\begin{array}{cc}
\mathbf{m}_{\beta}^{c 1} & \\
& \mathbf{m}_{\lambda}^{c 1} \\
\mathbf{m}_{\beta}^{c 2} & \\
& \mathbf{m}_{\lambda}^{c 2} \\
\mathbf{m}_{\beta}^{c B_{c}} & \\
& \mathbf{m}_{\lambda}^{c B_{c}}
\end{array}\right]\left[\begin{array}{c}
\boldsymbol{\beta} \\
\bar{\lambda}
\end{array}\right]+\left[\begin{array}{c}
\mathbf{v}_{\beta}^{c 1} \\
\mathbf{v}_{\lambda}^{c 1} \\
\mathbf{v}_{\beta}^{c 2} \\
\mathbf{v}_{\lambda}^{c 2} \\
\vdots \\
\mathbf{v}_{\beta}^{c B_{c}} \\
\mathbf{v}_{\lambda}^{c B_{c}}
\end{array}\right],\left[\begin{array}{c}
\mathbf{v}_{\beta}^{c 1} \\
\mathbf{v}_{\lambda}^{c 1} \\
\mathbf{v}_{\beta}^{c 2} \\
\mathbf{v}_{\lambda}^{c 2} \\
\vdots \\
\mathbf{v}_{\beta}^{c B_{c}} \\
\mathbf{v}_{\lambda}^{c B_{c}}
\end{array}\right] \sim N_{\left|\mathbf{v}_{\beta}^{c}\right|+\left|\mathbf{v}_{\lambda}^{c \mid}\right|}\left(0, \mathbf{I}_{B_{c}} \otimes \mathbf{\Omega}\right),
$$

with $\quad \mathbf{m}_{\beta}^{c b}=\mathbf{I}_{7} \otimes \mathbf{q}^{c b^{\prime}}, \quad \mathbf{m}_{\lambda}^{c b}=\mathbf{I}_{2} \otimes \mathbf{q}^{c b^{\prime}}$ and $\mathbf{q}^{c b^{\prime}}$ is a $(1 \times 5)$ vector of covariates. The hyperparameters relating these covariates to the actual first level response parameters are stacked in $\left[\overline{\boldsymbol{\beta}}^{\prime}, \overline{\boldsymbol{\lambda}}^{\prime}\right]^{\prime}=\left[\bar{\beta}_{0,1}, \bar{\beta}_{0,2}, \ldots, \bar{\beta}_{0,5}, \bar{\beta}_{1,1}, \ldots, \bar{\beta}_{6,5}, \bar{\lambda}_{0,1}, \ldots, \bar{\lambda}_{1,5}\right]$.

$\boldsymbol{\Omega}=\left[\begin{array}{ll}\boldsymbol{\Omega}_{11} & \boldsymbol{\Omega}_{12} \\ \boldsymbol{\Omega}_{12}^{\prime} & \boldsymbol{\Omega}_{22}\end{array}\right]$ is a full covariance matrix where $\boldsymbol{\Omega}_{11}=E\left(\mathbf{v}_{\beta}^{c b} \mathbf{v}_{\beta}^{c b}\right) \forall c, b$, $\mathbf{\Omega}_{12}=E\left(\mathbf{v}_{\beta}^{c b} \mathbf{v}_{\lambda}^{c b}\right) \forall c, b$, and $\mathbf{\Omega}_{22}=E\left(\mathbf{v}_{\lambda}^{c b} \mathbf{v}_{\lambda}^{c b}\right) \forall c, b$.

We use an MCMC approach to estimate the marginal distributions of the parameters and covariances. The MCMC algorithm involves sampling sequentially from the relevant conditional distributions over a large number of iterations. These draws can be shown to converge to the marginal posterior distributions. Our implementation of the MCMC algorithm has 4 steps that are described below.

\section{Conditional distributions}

The first implementation step requires that we specify conditional distributions of the relevant variables. The solutions of these distributions follow from the normality assumption of 
the disturbances terms. We employ natural conjugate priors. Specifications of the conditional distributions are as follows:

1. We draw the vector of parameters $\left[\boldsymbol{\beta}^{c 1}, \lambda^{c 1}, \boldsymbol{\beta}^{c 2}, \lambda^{c 2}, \ldots, \boldsymbol{\beta}_{c}^{c B}, \lambda^{c B_{c}}\right]^{\prime}$ from a SUR model with variance/covariance matrix of disturbances $\boldsymbol{\Sigma}_{c}$ :

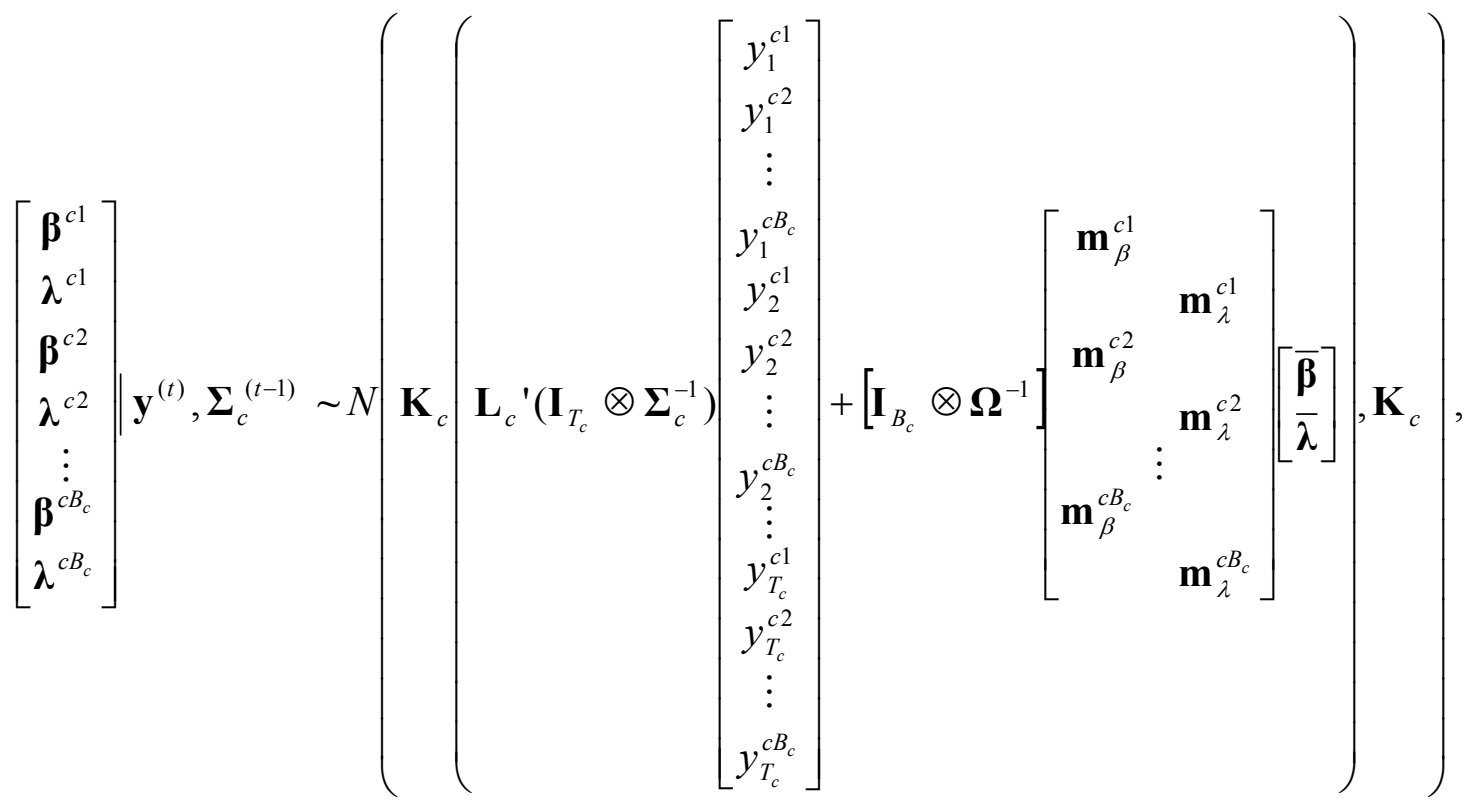

where $\mathbf{K}_{c}=\left(\mathbf{L}_{c}{ }^{\prime}\left(\mathbf{I}_{T_{c}} \otimes \boldsymbol{\Sigma}_{c}^{-1}\right) \mathbf{L}_{c}+\mathbf{I}_{B_{c}} \otimes \overline{\boldsymbol{\Omega}}^{-1}\right)^{-1}$, and

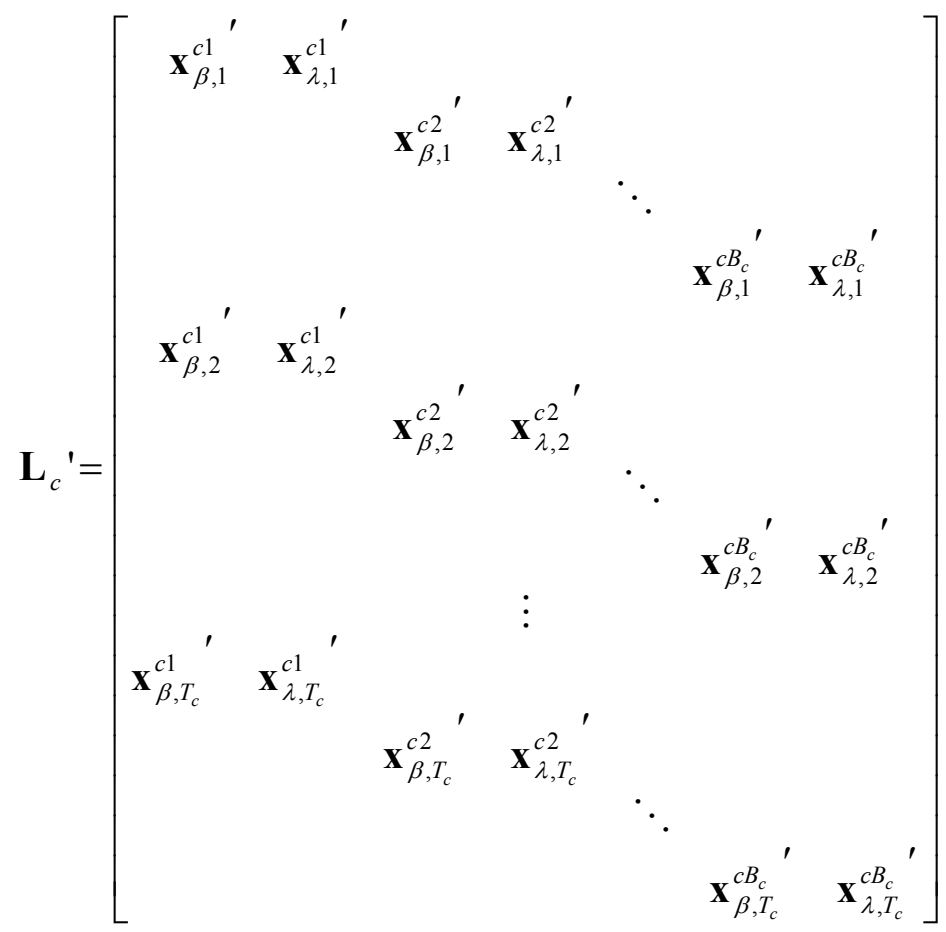


2. The vector of hyper-parameters, $\left[\overline{\boldsymbol{\beta}}^{\prime}, \overline{\boldsymbol{\lambda}}^{\prime}\right]^{\prime}$, is drawn from a SUR model with variance/covariance matrix of disturbances $\mathbf{\Omega}$ :

$$
\left[\begin{array}{l}
\overline{\boldsymbol{\beta}}^{(t)} \\
\overline{\boldsymbol{\lambda}}^{(t)}
\end{array}\right] \boldsymbol{\beta}^{(t)}, \boldsymbol{\lambda}^{(t)}, \mathbf{\Omega} \sim N\left(\mathbf{F}\left(\mathbf{G}^{\prime}\left(\mathbf{I}_{B} \otimes \mathbf{\Omega}^{-1}\right)\left[\begin{array}{c}
\boldsymbol{\beta}^{11} \\
\lambda^{11} \\
\boldsymbol{\beta}^{12} \\
\lambda^{12} \\
\vdots \\
\boldsymbol{\beta}^{1 B_{1}} \\
\lambda^{1 B_{1}} \\
\boldsymbol{\beta}^{21} \\
\lambda^{21} \\
\vdots \\
\boldsymbol{\beta}^{C B_{c}} \\
\lambda^{C B_{c}}
\end{array}\right]+\overline{\boldsymbol{\Omega}}^{-1}\left[\begin{array}{c}
\overline{\overline{\boldsymbol{\beta}}} \\
\overline{\bar{\lambda}}
\end{array}\right], \mathbf{F}\right),\right.
$$

with B the sum of all $B_{c}$ and hence the total number of brands.

3. We subsequently draw $\boldsymbol{\Sigma}_{c}$ from an inverted Wishart distribution with $T_{c}+v_{\Sigma_{c}}$ degrees of freedom:

$$
\boldsymbol{\Sigma}_{c}^{-1(t)} \mid \boldsymbol{\beta}^{(t)}, \lambda^{(t)}, \mathbf{y}, \mathbf{V}_{\Sigma_{c}}, \mathbf{v}_{\Sigma_{c}} \sim \text { Wish }\left(T_{c}+v_{\Sigma_{c}},\left(\mathbf{V}_{\Sigma_{c}}+\boldsymbol{\varepsilon}_{c}{ }^{\prime} \boldsymbol{\varepsilon}_{c}\right)^{-1}\right)
$$


4. $\Omega$ is drawn from an inverted Wishart distribution with $B+v_{\Omega}$ degrees of freedom:

$$
\boldsymbol{\Omega}^{-1(t)} \mid \boldsymbol{\beta}^{(t)}, \boldsymbol{\lambda}^{(t)}, \overline{\boldsymbol{\beta}}^{(t)}, \overline{\boldsymbol{\lambda}}^{(t)}, \mathbf{V}_{\Omega}, \mathbf{v}_{\Omega} \sim \operatorname{Wish}\left(B+v_{\Omega},\left(\mathbf{V}_{\Omega}+\left[\begin{array}{c}
\mathbf{v}_{\beta} \\
\mathbf{v}_{\lambda}
\end{array}\right]\left[\begin{array}{cc}
\mathbf{v}_{\beta}^{\prime} & \mathbf{v}_{\lambda}^{\prime}
\end{array}\right]\right)^{-1}\right)
$$

\section{Prior distributions}

We specify prior distributions for the parameters of interest. These are set to be non-informative so that inferences are driven by the data.

The prior distribution of $\left[\overline{\boldsymbol{\beta}}^{\prime}, \overline{\boldsymbol{\lambda}}^{\prime}\right]^{\prime}$ is $\mathrm{N}\left(\left[\overline{\overline{\boldsymbol{\beta}}}^{\prime}, \overline{\overline{\boldsymbol{\lambda}}}^{\prime}\right], \overline{\boldsymbol{\Omega}}\right)$, where $\left[\overline{\overline{\boldsymbol{\beta}}}^{\prime}, \overline{\overline{\boldsymbol{\lambda}}}^{\prime}\right]=0$ and $\overline{\boldsymbol{\Omega}}=\operatorname{diag}\left(10^{3}\right)$.

The prior distribution of $\Sigma_{c}^{-1}$ is Wishart: $W\left(v_{\Sigma_{c}}, \mathbf{V}_{\Sigma_{c}}\right)$, where $v_{\Sigma_{c}}=B_{c}+2$ and $\mathbf{V}_{\Sigma_{c}}=\operatorname{diag}\left(10^{-3}\right)$.

The prior distribution of $\boldsymbol{\Omega}^{-1}$ is Wishart: $W\left(v_{\Omega}, \mathbf{V}_{\Omega}\right)$, where $v_{\Omega}=3+2$ and $\mathbf{V}_{\Omega}=\operatorname{diag}\left(10^{-3}\right)$.

\section{Initial values}

The third implementation step is to set initial values for the parameters of the marginal distributions. The starting values for $\boldsymbol{\beta}$ and $\lambda$ are computed by OLS. The covariance matrix, $\Sigma$, is initiated by computing the sample covariances of this regression's residuals.

The final step is to generate $N_{1}+N_{2}$ random draws from the conditional distributions. We use a "burn in" of $N_{1}=20,000$ iterations. To reduce autocorrelation in the MCMC draws, we "thin the line," using every 25 th draw in the final $N_{2}=20,000$ draws for our estimation. In this way, 800 draws are used to estimate marginal posterior distributions of the parameters of interest. Test runs of our Gauss implementation of the MCMC draws show that we can retrieve parameters used to simulate artificial data. 